\title{
Psicologia, políticas educacionais e escolarização
}

\author{
Review Psychology, educational policies and schooling
}

\section{Reseña Psicología, políticas educativas y escolarización}

\author{
Maria Julia Lemes Ribeiro \\ Universidade Estadual de Maringá - Maringá - PR - Brasil
}

Zibetti, M.LT.; Souza, M.P.R.; Barroco, S.M.S. (Orgs.) (2015). Psicologia, Políticas Educacionais e Escolarização. Florianópolis: Pandion, 256 p.

As organizadoras da obra são docentes de três Universidades públicas brasileiras: Universidade de São Paulo, Universidade Federal de Rondônia e Universidade Estadual de Maringá, e constituem o quadro de professores efetivos dos Programas de Pós-graduação em Psicologia, além da relevante participação em projetos de pesquisa de mérito e reconhecimento no cenário acadêmico Nacional e Internacional em questões relativas á Psicologia Escolar e Educacional.

Logo na apresentação da obra, as organizadoras, também autoras dos capítulos junto a seus orientandos de Mestrado e Doutorado, esclarecem seu intento de partilhar com a comunidade acadêmica trabalhos produzidos na Pós-graduação das Universidades supracitadas, cuja temática circunda e articula aspectos políticos e teóricos sobre o conhecimento psicológico produzido na interface com a Educação, assim como aprofunda e extrai análises e reflexões importantes para uma leitura crítica e instigadora de ações com vistas a transformações no contexto educacional e político.

\section{Apresentando a obra}

A proposição de desvelar aspectos do cenário político que denunciam as desigualdades de oportunidades de acesso aos bens acumulados histórica e culturalmente se faz presente na obra à medida que aproxima a Psicologia das políticas educacionais e o compromisso com o desenvolvimento e aprendizagem escolar, o que é discutido no primeiro capítulo, "Ideologia e políticas públicas para a educação: reflexões necessárias".

No segundo capítulo, "Recuperação escolar: uma análise crítica a partir da Psicologia Escolar", e no terceiro, "Recuperação da aprendizagem no processo de escolarização: um estudo em Porto Velho-RO", os autores apresentam estudos sobre a recuperação escolar, em dois estados brasileiros, a saber: São Paulo e Rondônia. Utilizam os fundamentos da abordagem histórico-cultural e tratam de forma crítica aspectos da estrutura do programa de recuperação escolar - condizentes com as políticas estaduais empreendidas pelas Secretarias de Educação correspondentes, tendo como instrumentos de informação, regulamentações oficiais e depoimentos de educadoras, pais e mães de alunos. Ambos os estudos esclarecem a forma de tramitação das políticas educacionais que afetam diretamente a estrutura do funcionamento escolar e os rumos dados para a recuperação da aprendizagem no processo de escolarização.

Como parte da política de ampliação do tempo de estada da criança nas escolas públicas brasileiras, em que são organizadas e ofertadas atividades no contra turno para estudantes em condições de precariedade nos escores de avaliação pertinente ao índice de vulnerabilidade social, o quarto capítulo, "Programa Mais Educação: um olhar da psicologia sobre a ampliação da jornada escolar", informa, reflete e avalia as contribuições desta mudança para o processo de escolarização de alunos de uma escola pública de Porto Velho- RO. 
Também com a intenção de avaliar mais uma política educacional para recuperar dificuldades e ausência de domínio de leitura e escrita de estudantes da $3^{a}$ série do ensino fundamental de escolas da rede estadual paulista, o quinto capítulo, intitulado "Projeto Intensivo no Ciclo I: um estudo de caso etnográfico a partir da Psicologia Escolar", resgata a trajetória histórica das dificuldades de alfabetização nas escolas, apresentando os diferentes momentos de execução e ações políticas relacionadas, até a implantação do ainda atual Programa Ler e Escrever, onde está inserido o Projeto Intensivo no Ciclo I. Constituindo-se em uma pesquisa etnográfica, as análises foram realizadas a partir de material de campo, documentos oficiais e literatura, focando nos seguintes aspectos: condições de trabalho docente e práticas cotidianas em sala de aula.

Os dois outros capítulos que seguem, tratam da atuação do Psicólogo Escolar na Educação e são intitulados: "O psicólogo escolar na educação: possibilidades e desafios de uma atuação na perspectiva crítica" e "Psicólogos da rede pública de Educação: em busca de uma atuação institucional". Ambos apresentam análise sobre as práticas implementadas por esses profissionais da Psicologia no estado de São Paulo; o segundo enfatiza a atuação institucional, buscando caracterizar e compreender as concepções que subjazem a atuação e contribuições para a Educação.

Tendo como pano de fundo a articulação das políticas educacionais, Psicologia e Educação, no antepenúltimo capítulo, "Repercussões da formação de professores para a prática docente: investigando o cotidiano escolar", são relatadas reflexões sobre a formação continuada para professores da rede pública - Educação Básica do estado de São Paulo. Consistindo em um modelo de formação adotado nesta comunidade, apraz que seja avaliada a sua contribuição e adequação para responder aos desafios atuais do processo de escolarização.

No capítulo seguinte, "Políticas Públicas para a Educação Especial em Rondônia: entre tramas e entraves", as autoras analisam as políticas públicas que regulamentam e possibilitam o Atendimento Educacional Especializado neste estado, tendo como norte a aprovação da Lei de diretrizes e Bases da Educação Nacional - LDB 9494/96. Em suas análises, estão presentes aspectos que dizem respeito desde os equipamentos físicos, passam pela formação docente, implantação das Salas de Recursos Multifuncionais e principalmente, do funcionamento destes aspectos sob a consideração da premissa maior de desenvolver uma postura dos profissionais atuantes em relação à construção de uma prática inclusiva.

Por fim, é apresentado o tema das "Políticas públicas e processos educativos em Guiné-Bissau: contribuições da Psicologia Escolar brasileira no enfrentamento ao fracasso escolar", atrelado ao estágio pós-doutoral. Os autores destacam na constituição deste tema, como construto teórico e prático, a importância de pesquisas realizadas pelas três Universidades - UEM, USP e UNIR, cujas reflexões têm possibilitado extrapolar/ampliar suas análises para contribuir com a leitura crítica e transformadora de uma realidade que, com muitas dificuldades, vem enfrentando o fracasso escolar.

Apresentar a obra por meio de uma resenha que atinge um número significativo de pesquisadores acerca da Psicologia e sua interface com a Educação consistiu, neste momento, em um privilégio, no sentido da clareza de que a articulação dos três temas, Psicologia, Escolarização e Políticas Educacionais, possibilita uma leitura crítica e esclarecedora deste imbricamento, com vistas à construção de um processo que prime pela escolarização de todos os cidadãos, principalmente com foco nas populações com vulnerabilidade social. Certamente os estudos relatados contribuem para a reflexão, formação e atuação dos profissionais psicólogos e professores numa abrangência tal, que o compromisso da atuação priorize o compromisso ético, político e teórico das áreas envolvidas.

\section{Sobre a autora}

Maria Julia Lemes Ribeiro (mjlribeiro@uem.br)

Doutora em Educação, professora do Departamento de Psicologia (DPI) da Universidade Estadual de Maringá. 